\title{
Integrated BioBank of Luxembourg- University of Luxembourg: University Biobanking Certificate
}

\author{
Marcos Castellanos-Uribe, Sean T. May, and Fotini Betsou ${ }^{2}$
}

Keywords: biobank education, environmental biobank, biobank certificate

\section{Background}

$\mathrm{B}$ IOSPECIMENS HAVE BECOME a strategic tool for health care and medical research as well as for translational and systems biology studies through all types of omics applications. Animal and plant conservation research have also benefited from the use of biospecimens. In the past 15 years, optimal management of biospecimens and bioresources through biobanking has developed into a new discipline. ${ }^{1,2}$

Biobanking is multidisciplinary and covers aspects ranging from scientific, cryobiological, technical, and quality assurance topics to managerial, logistical, regulatory, and specific ethical issues. ${ }^{3}$ The Integrated BioBank of Luxembourg (IBBL), in collaboration with the University of Luxembourg, realized there was no university-level course on biobanking, be it academic or corporate that covered all these subjects. It was also evident that a transdisciplinary biobanking course would be very helpful to not just people working in biobanks, but also to those starting in this field that have the scientific background but not the practical experience in the management and operation of a biobank.

In an effort to share their biobanking expertise, IBBLUniversity of Luxembourg developed a lifelong learning course that uniquely combines environmental (animal, plant, and microbial) and clinical principles of biobanking into one transdisciplinary university certificate covering all technical, scientific, and ethical/legal aspects. The aim of the course is to provide the theoretical, operational, and practical knowledge required to facilitate the activities of existing biobanks and assist in the creation of new biobanks. It encourages exchange of knowledge and skills across different thematic groups involved in biospecimen conservation, storage, science, and research.

The course is taught by an experienced team of instructors representing different clinical, environmental, and biodiversity conservation disciplines, and takes place every 2 years at the University of Luxembourg and IBBL facilities. The University Biobanking Certificate was launched in June 2011 and has since been offered in 2013, 2015, and 2017. The course will take place again in June 2020.

\section{Methods: Learner and Curriculum Focus}

The University Biobanking Certificate is aimed at biobank staff, including managers, auditors, and technicians, as well as ethics committee members, clinical researchers, and pathologists. The course is presently designed for a maximum of 35 students per year. Prospective attendees should have a bachelor's degree or equivalent and an interest in biobanking and good knowledge of English. Online applications are reviewed by a committee of representatives of both IBBL and the University of Luxembourg. The tuition fee is 2000 euros (equivalent to USD 2300) and payment is required after the attendee's application is accepted.

The course is organized in the form of an intensive 3week seminar with a written examination at the end. It covers human clinical biobanking aspects and environmental biobanking aspects at the same time (e.g., microbial, stem cell, seed, and museum biobanking). By doing this, students can analyze and compare both clinical and environmental biobanks at each stage of the course. This approach fosters the development of new ideas and brings improvements to everyday practices and procedures as some techniques have been developed further in clinical biobanks whereas others are more predominant in environmental repositories. $^{3,4}$

The course incorporates site visits and practical demonstrations at IBBL, including nucleic acid extraction and characterization, cell sorting, progressive rate freezing, sample cryopreservation, and in vitro culture. Tutorial-based discussion sessions on different topics are also a fundamental component of the course such as development of a

\footnotetext{
${ }^{1}$ Plant and Crop Sciences Division, Nottingham Arabidopsis Stock Centre (NASC), University of Nottingham, Loughborough, United Kingdom.

${ }^{2}$ Integrated BioBank of Luxembourg (IBBL), Dudelange, Luxembourg.
} 
quality assurance document, process analysis, identification of quality indicators, and Standard Operating Procedure (SOP) analysis. The comprehensive curriculum includes:

- The biospecimen process chain (18 hours)

- Cryobiology (14 hours)

- Specimen transit and shipment (4 hours)

- Biobank statistics and strategies (5.5 hours)

- IT knowledge and management (5 hours)

- Risk management and mitigation (4 hours)

- Impact of preanalytical variations in research (16 hours)

- Quality management systems and assurance (12 hours)

- Regulatory, legal, and ethical aspects of biobanking (8 hours)

- Cost analysis and recovery (4 hours)

Upon completion of the course, participants should have a deep understanding of the common principles involved in practical biobanking as well as be able to put different types of biobanks in context and draw conclusions regarding the theoretical basis of their operations. They will gain an indepth understanding of the most critical parameters, both technical and scientific, that influence the quality of biospecimens. The main message that instructors try to communicate to students throughout the course is that biobanks provide biospecimens to end users performing research. Because of this, the quality of the biospecimen is of paramount importance for the reliability and validity of research results and further downstream applications. Critical thinking is a key component of the course: attendees are expected to question the logistical, practical, and technical steps in biobanking and evaluate their coherence and adequacy. Similarly, they will be able to produce biobank cost analysis and recovery reports by the end of the 3 weeks. On top of this, participants are expected to acquire the necessary knowledge to understand the legal aspects, ethical background, and contractual relationships between biobanks and different stakeholders.

Lectures take place at the University of LuxembourgCampus Limpertsberg from 9 am to 5:30 pm. Students also participate in different workshops designed to simulate reallife situations they might encounter at a biobank. Discussion is encouraged among participants; lectures and practical sessions usually last between 90 and 120 minutes as time is allocated for interactions and debates between students and instructors. All the lectures are printed and given to the students on the first day of the course. They also receive a compendium of relevant articles and publication as well as a collection of SOPs related to the most common biobanking procedures.*

The current operating costs associated with delivering this course are $\sim 40,000$ euros (equivalent to USD 45,000) per session. This figure includes administrative costs, food and beverage for the students, travel and accommodation for the lecturers, and annual updates of the scientific contents.

\section{Results: Participants and Feedback}

An average of 16 students per session have joined the University Biobanking Certificate since it began in 2011: 13

*Betsou, F. 2019. IBBL Bioservices. University Biobanking Certificate/ [Online]. Available from: https://www.ibbl.lu/wpcontent/uploads/2017/12/IBBL-University-biobanking-certificate.pdf in 2011, 18 in 2013, 19 in 2015, and 15 in 2017. Twenty-six countries have been represented from four different continents (Table 1).

At the end of the course, a survey/comments form is given to every student in which they have the opportunity to evaluate every aspect of the certificate program, from the content of the lectures to the quality of the University of Luxembourg-IBBL facilities. They are also encouraged to provide any suggestions that could improve the structure and content of the course. Feedback has been very positive so far, with $92 \%$ of students believing that the course accomplished their overall objectives. The headlines from the overall feedback can be summarized as follows:

- Students are pleased with the diversity of lecturers and instructors

- The transition from basic biobanking concepts to their practical application is valuable and keeps the course dynamic and interesting

- Ethical and legal aspects of biobanking are usually the highlight for a significant number of students

- Course is very useful for participants trying to establish a biobank in their home countries

- The course provides an invaluable networking opportunity

\section{Discussion}

At the moment, IBBL-University of Luxembourg will continue to offer the University Biobanking Certificate with the next session taking place in June 2020. Given the logistics of the course, June is the best option as this time frame coincides with the summer holidays in most northern hemisphere universities, thus allowing international students and lecturers the opportunity to attend.

Marketing of the course was initially conducted through presentations by IBBL staff members at annual European biobanking meetings, specifically the Technology and Methodology Platform for Networked Medical Research and the European and Middle Eastern Society for Biopreservation and Biobanking. These introductory presentations were mainly responsible for the initial student uptake during the first sessions of the course. Thereafter, word-of-mouth

Table 1. Number of Participants REGISTERED PER SESSION

\begin{tabular}{|c|c|c|}
\hline Year & $\begin{array}{l}\text { Number } \\
\text { of students }\end{array}$ & Countries represented \\
\hline 2011 & 13 & $\begin{array}{l}\text { Belgium, Egypt, Germany, Iceland, } \\
\text { Italy Malta, Sweden, and Switzerland }\end{array}$ \\
\hline 2013 & 18 & $\begin{array}{l}\text { Austria, Belgium, Egypt, Germany, } \\
\text { Italy, Lebanon, Luxembourg, } \\
\text { Qatar, Slovakia, and Sweden }\end{array}$ \\
\hline 2015 & 19 & $\begin{array}{l}\text { Brazil, Denmark, Germany, Japan, } \\
\text { Luxembourg, Qatar, Romania, } \\
\text { Saudi Arabia, Slovakia, Spain, } \\
\text { Sweden, Uganda, and the United } \\
\text { Kingdom }\end{array}$ \\
\hline 2017 & 15 & $\begin{array}{l}\text { France, Gambia, Germany, Japan, } \\
\text { Luxembourg, Poland, Russia, } \\
\text { Rwanda, United Arab Emirates, } \\
\text { and the United Kingdom }\end{array}$ \\
\hline
\end{tabular}


from former participants has been the most effective recruitment method by encouraging colleagues from their home biobanks/institutes to attend future sessions.

There are no significant changes planned to the course structure in the near-to-mid future. Comments from former students indicate that $83 \%$ of them are satisfied with the current format (3 weeks of intensive blended learning). Nevertheless, biospecimen science is a field that continues to change rapidly in both clinical and environmental biobanks. ${ }^{4}$ This ensures that the course program is updated for every session and specific topics can be changed and/or added if necessary. Communication between students and instructors continues well after course has finished and creates a unique network that can lead to new career opportunities.

It is clear that, although the University Biobanking Certificate has been very successful in attracting students from different backgrounds and countries, the main goal for future sessions is to double the number of participants that come from or work for environmental biobanks from $20 \%$ to $40 \%$. This increment will deliver a more balanced and richer experience to all students.

To conclude, the success of biobanks relies, among other things, on a set of skills and knowledge that will ensure future biobankers are able to provide high-quality biospecimens that are needed for research. ${ }^{5}$ Based on this, the University Biobanking Certificate represents the only continuing education program in Europe, complemented by an official examination, that gives the students a university certificate at the end of the 3 weeks.

Further information about the course, including a more detailed description of the program and the application process, can be found on the IBBL website.**

\section{Author Disclosure Statement}

No conflicting financial interests exist.

\section{Funding Information}

No funding was received.

\section{References}

1. Riegman P, Morente M, Betsou F, de Blasio P, Geary P. Biobanking for better healthcare. Mol Oncol 2008;2:213222.

2. Benson E, Betsou F, Harding K. Exploring standard preanalytical coding for environmental biospecimens using algal cryobanks as a case study. Cryobiology 2010;61:401401.

3. De Souza Y, Greenspan J. Biobanking past, present and future: Responsibilities and benefits. AIDS 2013;27:303312.

4. Betsou F. Biobanking education and training programs: A European perspective. Heidelberg: TMF Meeting; 2013.

5. Betsou F. Biobanking training in Europe. Leipzig: ESBB Meeting; 2014.

Address correspondence to: Marcos Castellanos-Uribe, PhD Plant and Crop Sciences Division Nottingham Arabidopsis Stock Centre (NASC) University of Nottingham Loughborough LE12 5RD United Kingdom

E-mail: marcos.castellanos@nottingham.ac.uk

**https://www.ibbl.lu/ibbl-bioservices/university-biobankingcertificate 